\title{
Dielectric analysis of different natural and synthetic polymers types
}

\author{
Hugo Salazar ${ }^{1}$, Pedro M. Martins ${ }^{1,2}$, C. M. Costa ${ }^{1}$, S. Lanceros-Méndez ${ }^{3,4}$ \\ ${ }^{1}$ Centro de Física, Universidade do Minho, 4710-057 Braga, Portugal \\ ${ }^{2}$ Institute of Science and Innovation for Bio-Sustaninability (IB-S), University of Minho, \\ 4710-057 Braga, Portugal \\ ${ }^{3}$ BCMaterials, Basque Center for Materials, Applications and Nanostructures, UPV/EHU \\ Science Park, 48940 Leioa, Spain \\ ${ }^{4}$ IKERBASQUE, Basque Foundation for Science, 48013, Bilbao, Spain
}

\section{Introduction}

Polymers, also called macromolecules, have originated a technological revolution in different technological areas, including automotive and aerospace industries and even electronics, allowing to obtain light, flexible and robust materials with tailored physicochemical properties [1].

Most polymers are dielectric materials and it is possible to tailor specific properties, including electrical, mechanical and thermal properties, for the most technologically demanding application [2].

However, it is essential to understand the dielectric response of polymer material due to the different possible contributions: microscopic fluctuations of the molecular dipoles, propagation of the charge carriers, ions or charge gaps, and charge separation at the various interfaces (Maxwell-Wagner-Sillars contribution) that cause additional polarization contributions [3, 4].

In addition, the relaxation processes in polymer systems are characterized by a distribution of relaxation times that can be described according to various functions based on different empirical models (Debye, Cole-Cole, Cole-Davidson and Havriliak-Negami) allowing to extract a variety of relevant parameters revealing the nature and main characteristics of the observed relaxations $[5,6]$.

Recently, there is a demand for natural polymers to replace synthetic polymers derived from fossil fuel and, therefore, this chapter will focus on the dielectric response of the most relevant natural polymers after a brief introduction to the dielectric response of the main synthetic polymers. 


\section{Overview of the dielectric response of polymers}

The response of a dielectric material when an electric field is applied is defined by the dielectric permittivity. The dielectric permittivity is a complex function describing the ability of a material to store electrical energy $\left(\varepsilon^{\prime}\right)$ and the ability to dissipate energy into heat $(\varepsilon ')[7]$. These two parameters define the dielectric character of a material, according to equation 1 .

$$
\varepsilon=\varepsilon^{\prime}-j \varepsilon^{\prime \prime}
$$

where $\varepsilon^{\prime}$ is the real dielectric constant and $\varepsilon^{\prime \prime}$ is the imaginary dielectric constant that is related to the electrical conductivity.

Polymers can be classified as polar or apolar (Figure 1), due to their chemical structure [8]. Apolar polymers are efficient isolating materials, and they show dielectric loss values around $10^{-4}$ to $10^{-3}$ and a quasi-constant dielectric permittivity of 2.5 to 3 , even with changes of frequency and temperature. This type of polymers is usually composed of carbon and hydrogen atoms symmetrically disposed all along a carbon chain. Polyethylene and poly(tetrafluoroethylene) are two examples of apolar polymers. In contrast, polar polymers are usually composed of molecules with electronegative atoms, like oxygen, nitrogen, fluoride or chloride, which provide dipoles to the polymer structure. They are characterized by higher dielectric constant and loss factor, about 3.5 to 10 and $10^{-2}$ to $10^{-1}$, respectively. An example of polar polymers are proteins, and their polar character depends on their lateral amino acids chain.

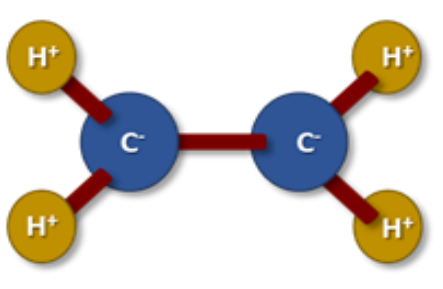

(a)

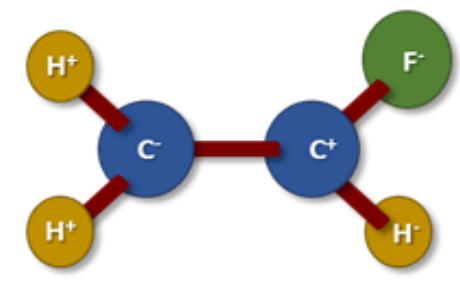

(b)

Figure 1 - (a) Polyethylene apolar polymer and (b) poly(fluoroethylene) polar polymer. 
The polarization of a material occurs with the variation of the dipolar moments when an electric field is applied. Polarization can be originated by several effects such as charge accumulation at materials interfaces with layers having different dielectric constants (interfacial polarization), dipolar reorientation, atomic or electronic polarization [9]. All these polarization types contribute to the dielectric constant value and are responsible for two phenomena: relaxations happening till $\mathrm{THz}$ and resonances happening above $\mathrm{THz}$ [10]. Dielectric permittivity and loss can be represented on a wide range of frequencies, as presented in Figure 2.

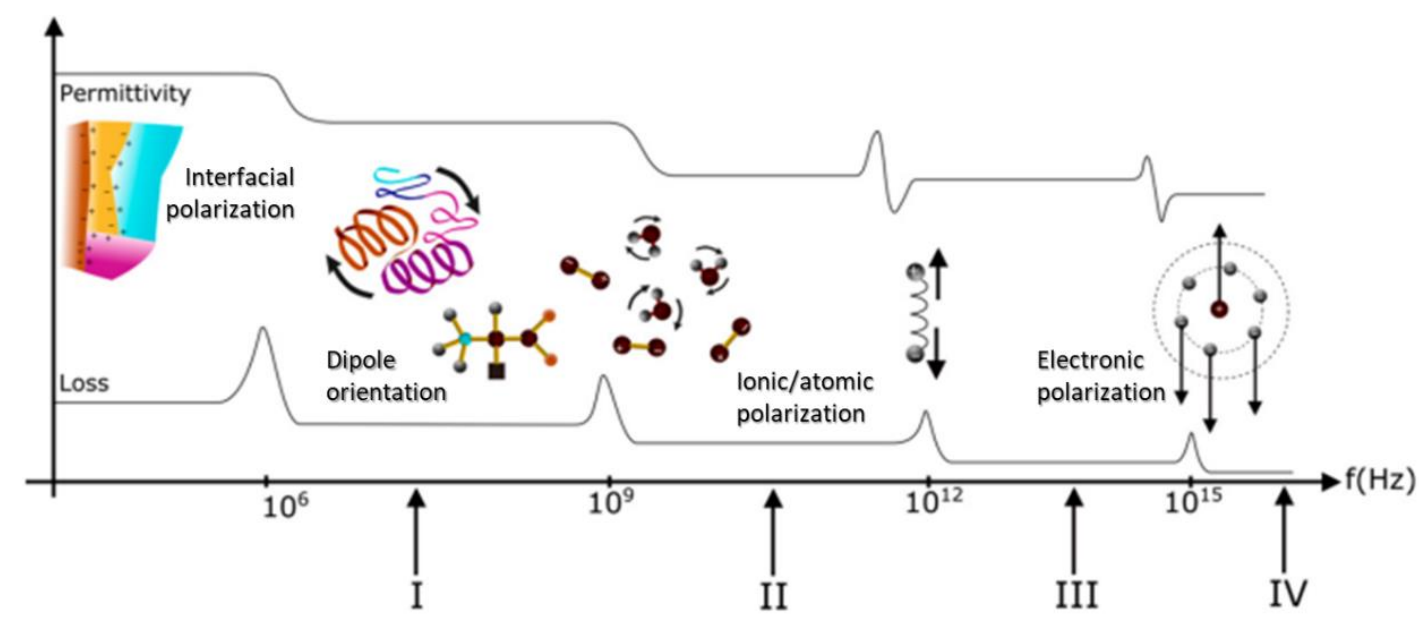

Figure 2 - Influence of different types of polarization on the dielectric response: (I) radio; (II) microwave; (III) infrared-visible and (IV) ultraviolet frequency ranges (adapted from $[8])$.

According to Figure 2, four main types of polarization can be considered. At lowfrequency ranges, the different polarization effects contribute to higher dielectric constants. With increasing frequency, some dipolar contributions disappear, leading to a decrease in the dielectric constants.

The first type of polarization is interfacial polarization, which occurs at low frequencies $\left(<10^{6} \mathrm{~Hz}\right)$ in heterogeneous materials, due to the limited displacement of free charges and their accumulation at interfacial areas and borders between different phases of the materials with different permittivity values. This type of polarization is present in solid and liquid dielectrics, usually in heterogeneous or amorphous structures [8]. 
The second type of polarization, dipole orientation, is the orientation of polar or apolar molecules under an electric field at high frequency $\left(10^{6}\right.$ to $\left.10^{10} \mathrm{~Hz}\right)$, due to the rotation of charged side groups and relaxation of water interacting with the molecules. They usually present dielectric constants of 4 to 5 at low hydration levels and up to 10 at high hydration levels. In contrast, the dielectric loss values are low $\left(10^{-3}\right.$ to $\left.10^{-2}\right)$ and can vary with temperature, humidity, and frequency [8].

Atomic and ionic polarization results from the displacement of atoms bonded through ionic bonds. Valence electrons move along shared orbits with other atoms, creating an induced dipole. Ionic bonds are usually found in inorganic solid dielectric polymers with a crystalline structure [8].

The last type of polarization is the electronic polarization, which is present in all types of dielectric polymers at high-frequency values $\left(10^{13} \mathrm{~Hz}\right)$. This phenomenon results from the displacement in relation to the atomic nucleus, leading to temporary dipoles that disappear as soon as the electric field is removed [8].

$\operatorname{XXXXX}$

\section{Natural polymers}

The scarcity and lower performance for different applications of natural polymers has led to the development of synthetic polymers such as nylon, polyethylene, acrylic, 
and neoprene, among others [11]. The increasing use of synthetic polymers is related to the large possibilities of modification of their chemical structure that allows obtaining products with specific properties. However, this unrestrained use of petroleum products has created a double dilemma: decrease of oil resources and the introduction of plastics into the food chain and environment [12]. Another problem with synthetic polymers is that their disposal in landfills creates a serious aesthetic problem in urbanized areas of the world, as the chemical stability of the plastic prevents the waste from decomposing into the environment at a rate comparable to the rate of waste generation. Through water it is also possible to transport large quantities of plastic waste over long distances, creating a mobile contamination problem. Plastic waste corresponds to $60 \%$ to $80 \%$ of accumulated marine waste. The problem of marine waste is worsened by the low efficiency of removal technologies aimed at reducing the residual concentration of marine plastic in the oceans. The effects on marine life of plastic waste include the ingestion of harmful plastics by marine animals and the bioaccumulation of toxic substances along the food chain. The exhaustive use of these resources has initiated the search for the development of biodegradable plastics, based on biologically based renewable plants and agricultural products that can compete in markets currently dominated by petroleum derived products [13].

Natural polymers are a specific class of polymeric materials which are present or created by living organisms and renewable resources such as starch, lignin, cellulose or hemicellulose, among others. This kind of polymeric materials is biodegradable, which means that the polymer loses its weight due to the chain scission of the backbone by degradation processes, resulting in compounds with lower molecular weight. There are two types of natural polymers: some come from living organisms, such as carbohydrates and proteins, and some need to be polymerized from renewable sources, such as lactic acid and triglycerides. Both can be polymerized to create bioplastics. Natural polymers, or biopolymers, can be classified according to their sources. The classification is shown in Figure 3. 


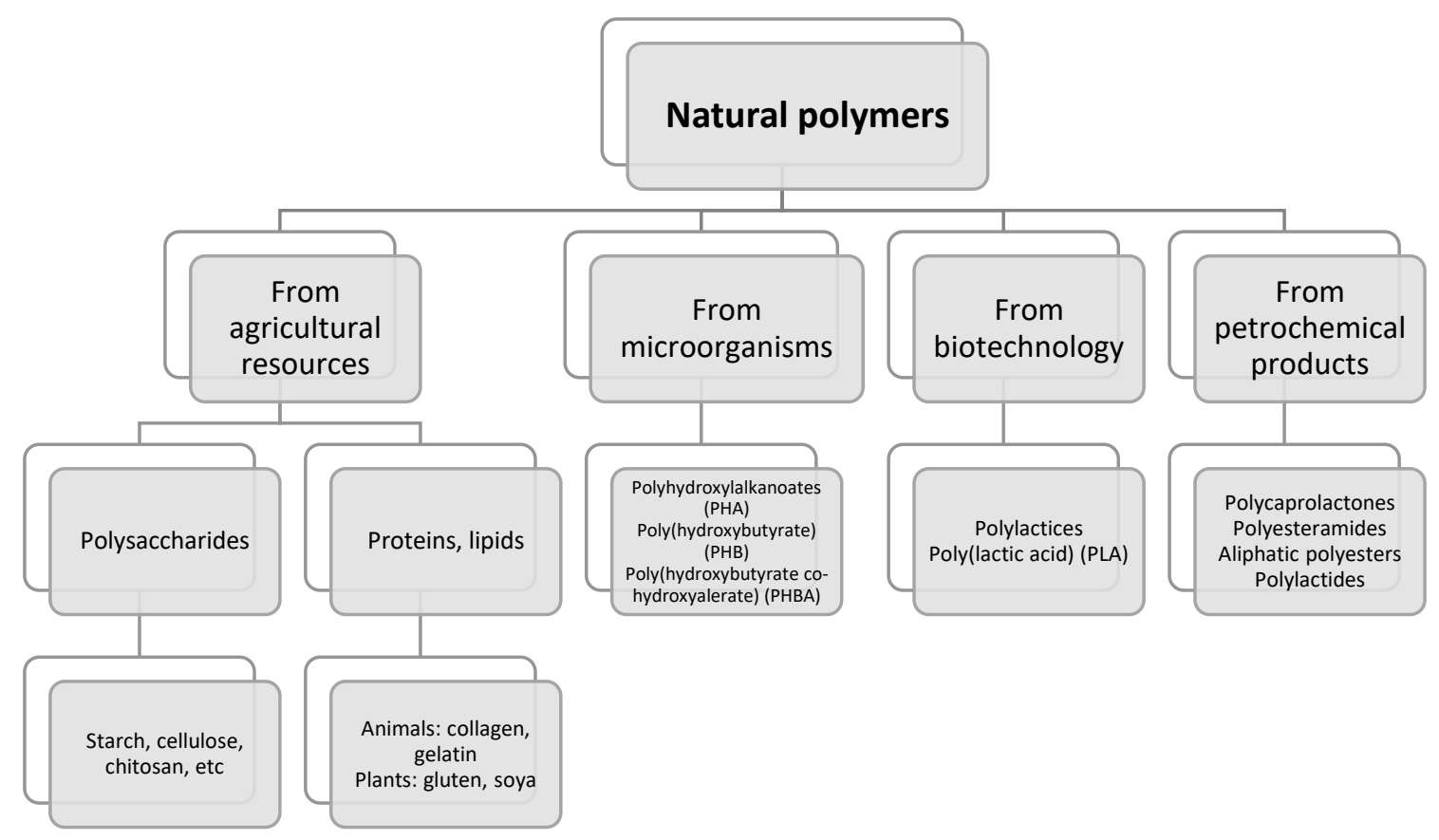

Figure 3 - Natural polymers classification according to their sources (adapted from [14]).

From all different sources, the best-known resources for biopolymers are starch and cellulose. Cellulose is the most abundant carbohydrate in the world (40\% of all organic matter is cellulose), is the main constituent of plants and responsible for maintaining its structure, being a substitute for petroleum feedstocks to develop cellulose plastics. Cellulose can also be found in bacteria, fungi, algae and even in animals. Cellulose from cotton trees and plants is an ideal substitute for petroleum raw materials to make cellulose plastics [15].

Biopolymers have been applied in a large variety of industries, like textiles, packaging, fast food containers, lawn and garden waste bags, paper coating, agriculture mulch films, toys, tubes, medicinal products, disposal wipes, erosion control, biologically based resins, car parts, glass fibers agents, adhesives, and coatings, among others. Biopolymers like polycaprolactone (PCL) are processed in the production of spun fibers, scaffold fibroblasts and myoblasts, tissue engineering, electro-spun fibers, and seatbelts. Polysaccharide and protein-based biopolymers can be used as coatings and biofilms to enhance the quality of fruits and vegetables by preventing deterioration, providing a modified atmosphere for a shelf-life extension [16].

When compared with synthetic polymers, the stiffness and strength of biopolymers, especially from starch, shows advantages. Also, they are biodegradable and renewable as 
well as edible. Also, biopolymers are known to be biocompatible and non-toxic, show low cost and local availability. However, they have relatively poor mechanical and water vapor barrier properties. Other disadvantages of natural polymers are the microbial contamination, the batch to batch contamination, the uncontrolled rate of hydration, the slow processing and the heavy metal contamination.

\subsection{Amorphous polymers}

\subsubsection{Xanthan gum}

Xanthan gum $(\mathrm{XG})$ is a bacterial polysaccharide obtained from microbiological fermentation, in anaerobic conditions, of carbohydrates like sugar cane and corn, being transformed into a soluble gum by a reaction with presence of the bacteria Xanthomonas campestris. XG is an acidic biopolymer composed by pentasaccharide subunits with branched chains, forming a cellulose backbone with trisaccharide side-chains of mannose $(\beta-1,4)$ glucuronic acid and $(\beta-1,2)$ mannose attached to alternate glucose residues in the backbone by $\alpha-1$, three linkages [17], as shown in Figure 4.

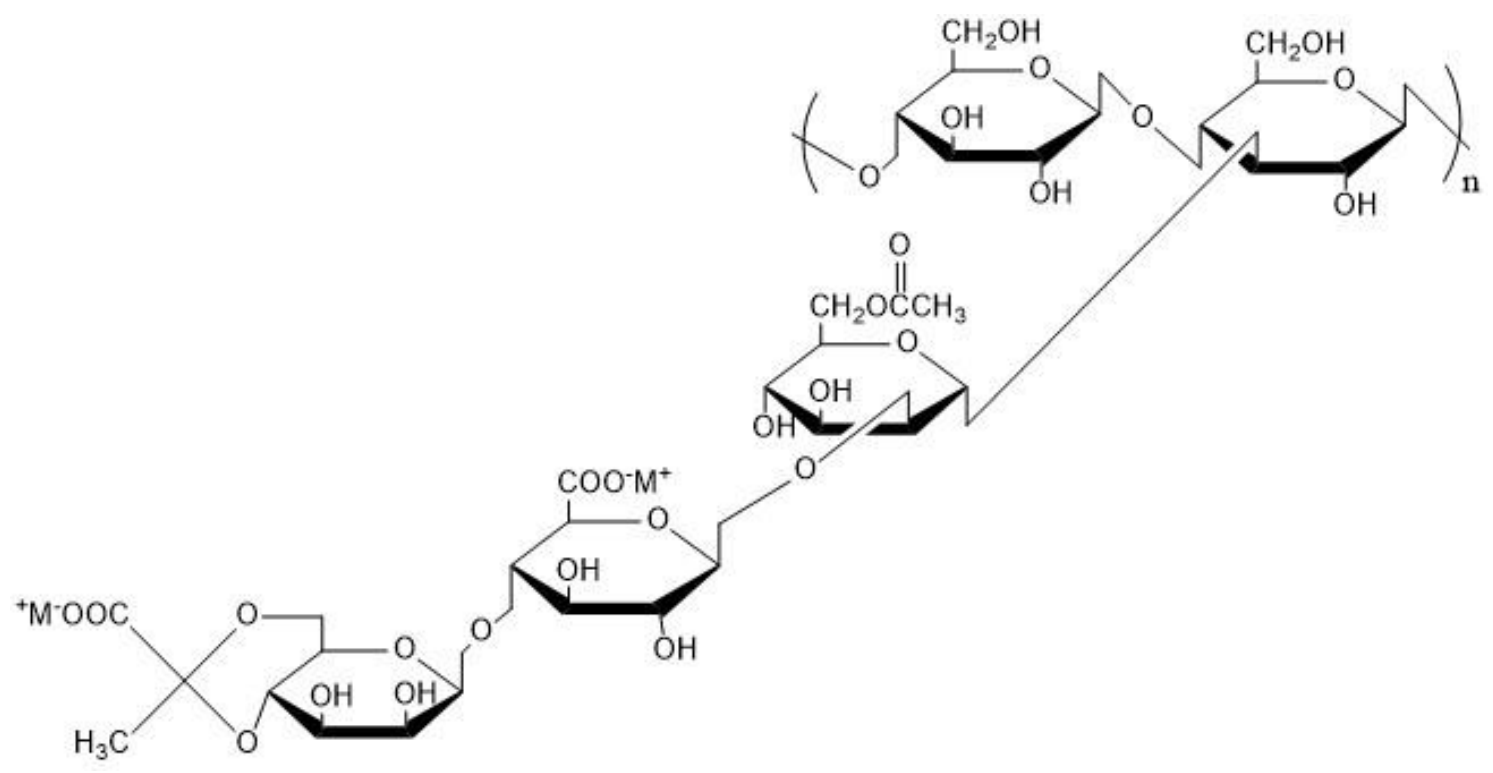

Figure 4 - Chemical structure of xanthan gum.

When in solution, XG has excellent thermal stability, proved by its uniform viscosity over a wide range of temperatures from freezing to near boiling. XG also shows good stability and solubility, even when doped with acids, bases or salts and excellent biocompatibility. XG is commonly used in the food, cosmetic, textile, pharmaceutical and 
petroleum industries. Also, some studies show the applicability of XG as gel polymer electrolyte in a capacitor [17] or as a rate-controlling polymer for drug release [18].

The dielectric constant of rice cake batters with xanthan gum is 2.855 and the dielectric loss is 0.202 [19]. The effect of the presence of xanthan gum in bread leads to a dielectric constant close to 24 and a dielectric loss of 10 [20].

\subsubsection{Carrageenan}

Carrageenan is a linear sulfated polysaccharide and is the main constituent of the extracellular matrix of red algae such as Euchema nuricatum and Gracilaria lemaneiformis. Generally, carrageenan has a backbone of D-galactose with alternating $\alpha$ 1,3 and $\beta-1,4$ linkages. There are three main types of carrageenans: the $\kappa-$, the $1-$ and the $\lambda$-carrageenans, which differ on the number and position of sulfate substitutions and the location of 3, 6-anhydro bridge in $\alpha$-1, 4-linked galactose residues. These three carrageenan types are shown in Figure 5.

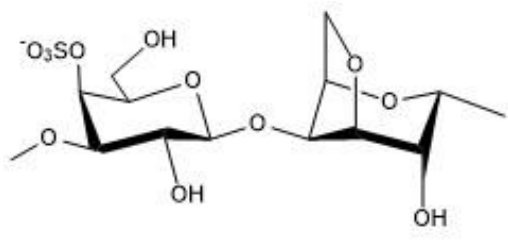

Kappa-carrageenan

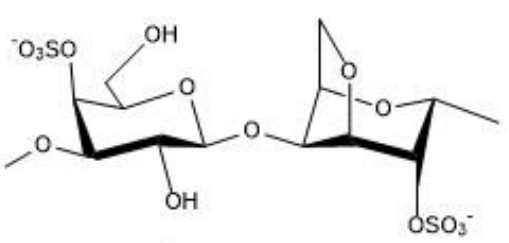

Iota-carrageenan

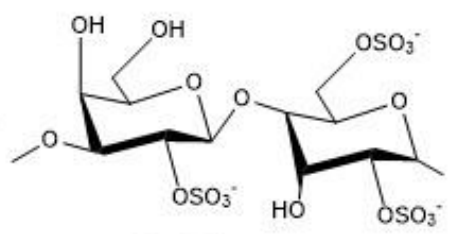

Lambda-carrageenan

Figure 5 - Chemical structure of carrageenan.

Carrageenan has been widely used in food, beverage, and cosmetic industries as thickening, clarification and gelling agents due to the excellent properties, such as gelforming ability, chemical stability, and various physiological activities. However, this biopolymer has poor solubility and low bioavailability.

The dielectric constant of rice cake batters with carrageenan is 2.951 , and the dielectric loss is 0.232 [19]. The dielectric constant is frequency dependent and the dielectric constant values decrease from 100 to 10 with increasing frequency from $10^{0}$ to $10^{6} \mathrm{~Hz}$ [21]. Another work shows the decrease of dielectric constant values from 100 to 50 with increasing frequency (from $10^{8}$ to $10^{10} \mathrm{~Hz}$ ) and the corresponding decrease of dielectric loss from 200 to values close to 0 [22]. 


\subsubsection{Gelatin}

Gelatin is a natural polymer, derived from collagen by acid and alkaline processing, obtained from animal skins, and bones, among others. During this process, collagen is transformed into an unoriented water-soluble protein with quasi-reversible water dissolving property. It is a mixture of single or multi-stranded polypeptides composed by proline, hydroxyproline, and glycine (Figure 6) [23]. Gelatin is usually used for pharmaceutical and medical applications due to its biodegradability and biocompatibility in physiological environments. It can also be a suitable dielectric material for the production of memristors [24].

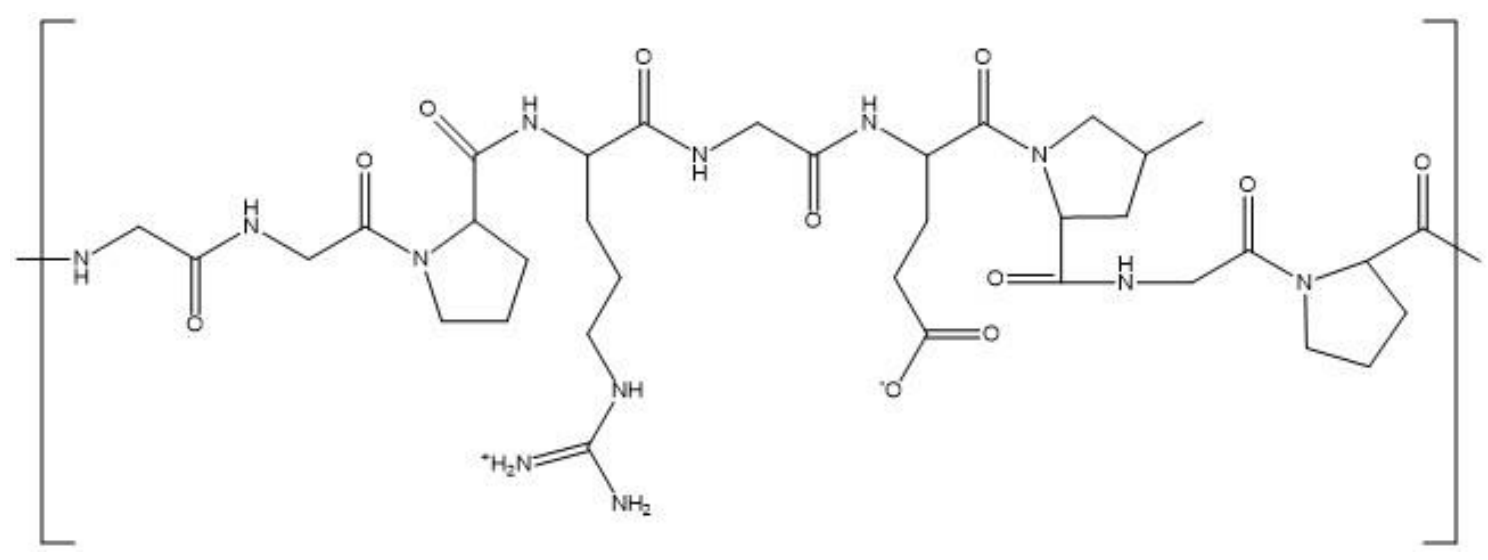

Figure 6 - Chemical structure of gelatin.

Two different types of gelatin can be produced according to its processing and collagen pretreatment. The acidic method does affect the amine groups present while the alkaline method targets the amine groups of asparagine and glutamine with a higher density of carboxyl groups. This results in electrically different gelatin [25].

The dielectric constant of single-wall carbon nanotubes-based gelatin phantoms was reported to decrease from 75 to 30 with increasing frequency [25] from 1 to $20 \mathrm{GHz}$ [26]. The thermoplastic gelatin was evaluated according to its dielectric constant and conductivity [27], the dielectric constant decreasing from $10^{8}$ to 10 with increasing frequency from $10^{-2}$ to $10^{5} \mathrm{~Hz}$.

\subsubsection{Ispaghula}


Ispaghula, also known as psyllium, is a natural, gel-reduced and water-soluble material derived from the husks of the seeds of Plantago ottava, being used in India and China as herbal medicine to treat skin irritations, high blood pressure, and bladder problems. It is a polysaccharide with a high percentage of hemicellulose, like other polysaccharides. It is a hydrophilic material, with water uptake properties and gelling capabilities, but it is not $100 \%$ water-soluble, consisting of $35 \%$ of soluble and $65 \%$ of insoluble polysaccharides [29]. Its gelatinous mass and swelling properties make it suitable for absorption and drug delivery systems. Ispaghula has also wound healing and cholesterol-lowering properties, and it is being used as part of colon cleansing programmes in the prevention of colon cancer. Ispaghula plays an important role in medical and human health management, and it is widely used as a safe and effective laxative and can be taken internally as a dietary supplement due to its low acute toxicity. Also, it is used in the maintenance of the health of the digestive system and in the prevention of cardiovascular diseases, cancer, diabetes and other diseases [29]. There are no works regarding the study of dielectric properties of ispaghula.

\subsection{Semicrystalline polymers}

\subsubsection{Poly (lactic acid)}

Poly (lactic acid) (PLA) is a thermoplastic polymer derived from renewable raw materials like corn starch and sugarcane, which are fermented to lactic acid. After that, the lactic acid is polymerized to PLA (Figure 7) [30]. Due to its mechanical and biological properties, like biodegradability, biocompatibility, lightweight, and flexibility, PLA is widely used in clinical and biomedical applications. In biomedical applications, PLA is applied in nanoimprinted platforms for tissue regeneration, because the degradation products are not toxic to culture, cellular processes, and metabolism [31]. It is also used in electronic components, like for example patch antennas [32], microelectromechanical systems [33] and printed circuit boards [34]. 


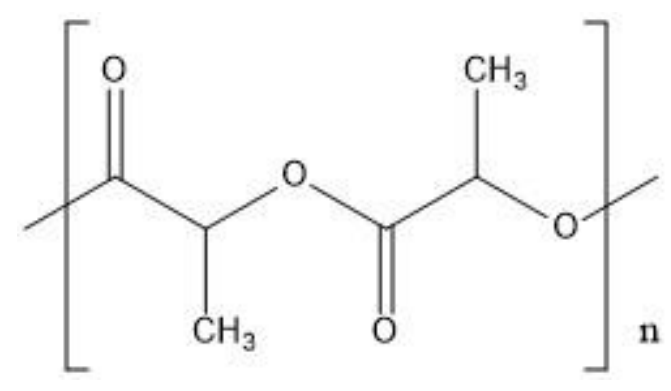

Figure 7 - Chemical structure of PLA.

The study of the dielectric properties of PLA is of great scientific and practical interest. The dielectric constant of PLA in the range of frequencies from 1 to $60 \mathrm{GHz}$ reveals a decease of the dielectric constant from 2.9 to close to 2.5 with increasing frequency [30]. The dielectric constant behavior with the variation of temperature reveals and increase of the dielectric constant from 2.9 to 5 when temperature increases from room temperature to $400 \mathrm{~K}[36]$.

\subsubsection{Polyhydroxyalkanoates}

Polyhydroxyalkanoates (PHA) are a family of linear polyesters, naturally produced through bacterial fermentation. PHA is a family of polymers, where more than 150 monomers have been discovered that can combine to yield polymers with diverse properties. A big variety of PHA-producing bacteria is known, and these bacteria produce PHA using renewable waste feedstock, like vegetable oils, gas, lignocellulosics and fatty acids [37]. These materials are constituted by carbon, hydrogen, and oxygen, with each monomer unit harboring a side chain, an R group, as shown in Figure 8. The nomenclature of PHA is given by the functional group of the side chain, R group [38].

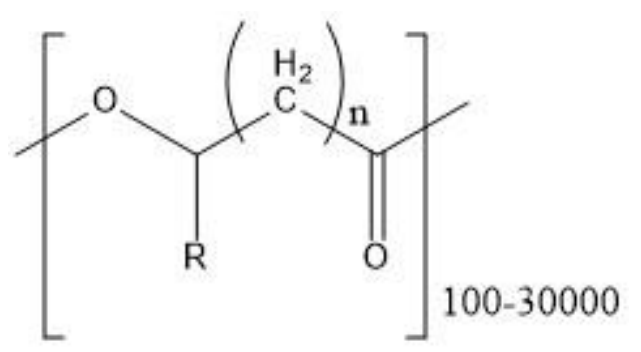

Figure 8 - Chemical structure of polyhydroxyalkanoates. 
PHA is formed intracellularly by bacteria, and they are stored in its cytoplasm, as inclusion bodies. These biopolymers can find applications in various fields of human activity, due to their thermoplasticity, high antioxidant properties, optical activity and the compatibility with living tissues. PHA can be classified into two different types, according to the carbon number: short-chain PHA, containing 5 or fewer carbons; and medium-chain PHA, containing 6-14 carbons in the monomer. The type of PHA produced depends on the type of polymer synthase present in the organism. The mechanical, thermal and dielectric properties of PHA depend upon copolymer composition [39], the value is influenced by the temperature and frequency, having a minimum of 2.2 at $-100^{\circ} \mathrm{C}$ and $10^{6} \mathrm{~Hz}$ and a maximum of XXXX at $50^{\circ} \mathrm{C}$ and $1 \mathrm{~Hz}[40]$.

Poly ( $\beta$-hydroxybutyrates) (PHB) is one of the most studied polyhydroxyalkanoates with a dielectric constant between 2 and 7 with the variation of temperature between -120 ${ }^{\circ} \mathrm{C}$ and $30{ }^{\circ} \mathrm{C}[41]$.

\subsubsection{Polybutylene succinate}

Polybutylene succinate (PBS) is a biopolymer resulting from esterification of succinic acid with 1,4- butanediol, and eventually a third monomer (figure 9). This is a two steps process, starting with the reaction of succinate acid with 1,4 - butanediol to form PBS oligomers. The second step is the catalytic esterification to form a high molecular weight PBS. It is derived from fossil materials but can be completely biobased depending on the monomers. It is a crystalline and aliphatic polymer, and its mechanical and thermal properties depend on the degree of crystallinity. PBS has mechanical properties similar to polypropylene, with good tensile and impact strength, which depend on the molecular weight of the polymer. However, the price of PBS when compared with PP prevents it to substitute PP in most of the applications [37].

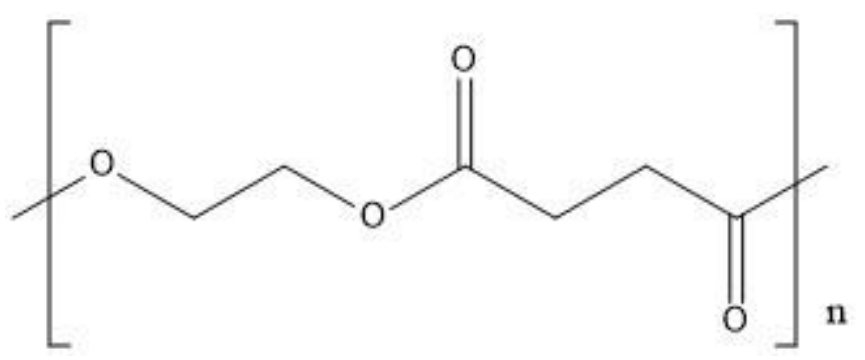

Figure 9 - Chemical structure of PBS. 
The dielectric constant of PBS increases from 3.5 to 4 with increasing frequency from 0 to $20 \mathrm{MHz}$ [42]. With the increase in temperature, the dielectric constant increases, with the maximum value of 100 to temperature values of $363 \mathrm{~K}$ [44].

\subsubsection{Cellulose}

Cellulose is one of the most abundant biopolymers on earth. The most common lignocellulosic material can be found in tree wood, and other materials containing cellulose are grasses, plants, and agriculture residues. It is a polymer formed by D-glucose monomers linked through $\beta$ (1-4) glycosidic bonds (Figure 10). This structure produces linear polymeric chains with high polar surface due to the multiple hydroxyl groups. As a result, cellulose chains join to form micro-fibrils which lead to a very high tensile strength and elastic modulus. Cellulose-based polymers are derived from various plants and microorganisms and present different properties and applications. For example, rice husk cellulose is used as animal husbandry, pest control, and absorbents, while rice husk ash powder produced through combustion processes is used as refractory bricks, steel and as additional filler in partial cement replacements. All of them have been widely used as biodegradable natural filler in polymer composites [45].

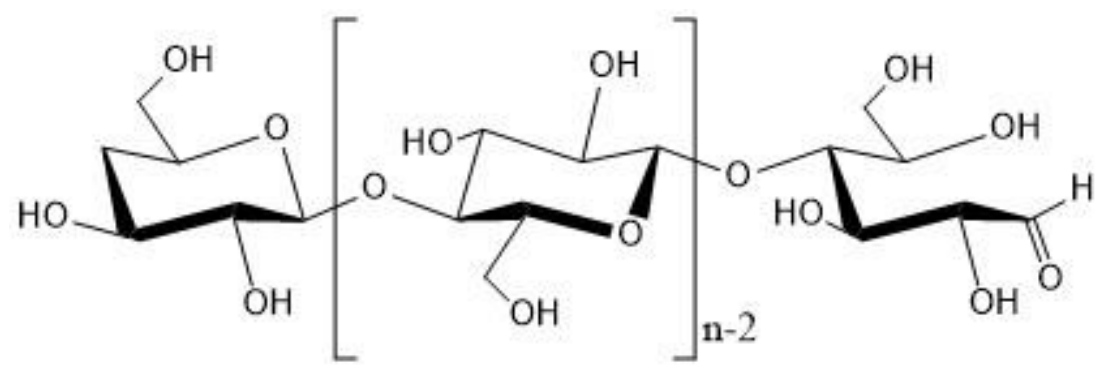

Figure 10 - Chemical structure of cellulose.

The dielectric constant of bacterial cellulose composites [46] decreases from 2.52 to 1.78 with increasing frequency from $10^{2}$ to $10^{6} \mathrm{~Hz}$. The dielectric constant of cyanoethyl cellulose membranes is not affected by the increase of frequency from 1 to $107 \mathrm{~Hz}$, but it is affected by the solvent, with variations from 1.5 to 6 [48].

\subsubsection{Alginate}


Alginate is a biopolymer extracted from seaweeds (figure 11), where it is present as a cell wall component, with structural functions similar to other biopolymers like agar and carrageenan. Alginate can be extracted from seaweeds through three different processes: the dissolution of the alginic acid present on seaweed biomass with an alkaline solution; precipitation of sodium alginate with calcium chloride and filtration; by purification and drying processes. Alginate is widely used in food applications, paper coating, textile printing paste, wound dressings, pharmaceuticals and others [49] due to its gelling, thickening and film-forming properties.

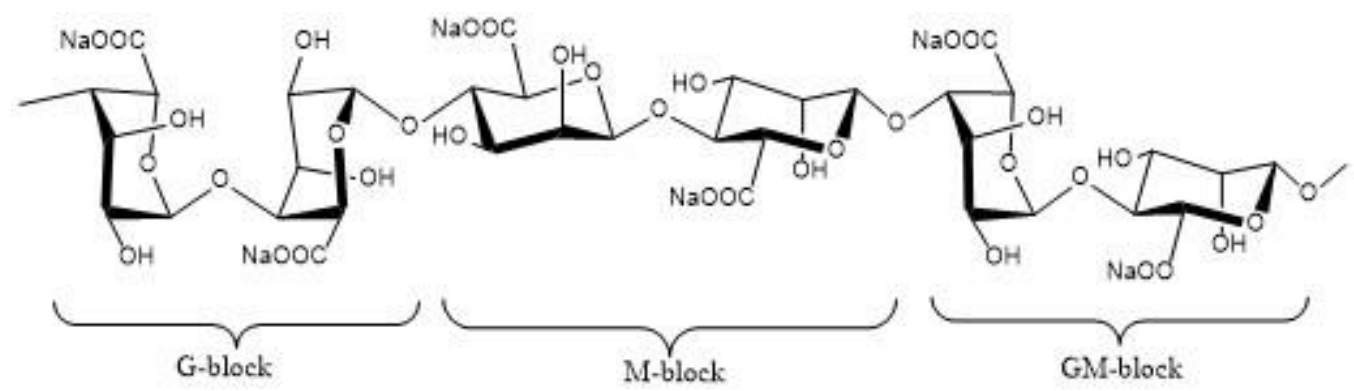

Figure 11 - Chemical structure of alginate.

Its dielectric constant decrease from 100 to 50 with increasing frequency from $10^{8}$ to $10^{10} \mathrm{~Hz}$ and the dielectric loss decreases from 250 to values close to 0 with the same increase of frequency [22].

\subsubsection{Polyisoprene}

Polyisoprene is a biopolymer based on rubber bridges (figure 12). There are two types of polyisoprenes: cis-polyisoprene, which is a natural rubber obtained from the tree Hevea brasiliensis; trans-polyisoprene, produced by Pallaquium gutta. Cis-polyisoprene has good mechanical properties, like elasticity and softness. In comparison to transpolyisoprene, it has a lower molecular weight and worse mechanical properties, as it is hard and brittle. Polyisoprene presents high performances regarding malleability at cold temperatures, resilience, impact resistance, abrasion and efficient heat dispersion [51]. 


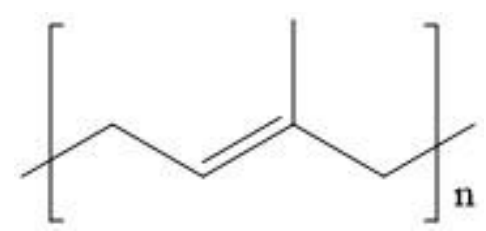

Figure 12 - Chemical structure of polyisoprene.

The dielectric constant of polyisoprene at a constant temperature of $65^{\circ} \mathrm{C}$ varies from 2.36 to 2.28 with increasing frequency [52]. The dielectric constant of transpolyisoprene is not affected by the frequency and presented a constant value of $\approx 4.7$ with increasing frequency from 0.1 to $10 \mathrm{GHz}$ [53].

\subsubsection{Starch}

Polysaccharides represent by far the most abundant biopolymer class of the earth, with cellulose, chitin, and starch dominating. Starch is the largest reserve of carbohydrates in plants. In contrast to cellulose, it can be digested by humans and represents one of the main sources of energy that sustains life [54]. Starch is one of the most versatile materials for potential use in polymers. It can be converted to chemicals such as ethanol, acetone and organic acids, used in the production of synthetic polymers, to produce biopolymers by fermentation processes or to be hydrolyzed and employed as a monomer or oligomer. Also, it can be used with a variety of reagents to produce new polymeric materials, which can be used as polymers or as fillers to other polymers [55].

The starch used in industrial applications is usually extracted from cereal seeds (corn, wheat, and rice), tuber and roots. Starch is essentially composed of two main polysaccharides, amylose and amylopectin, and some minor components such as proteins and lipids [56]. The chemical structures of amylose and amylopectin are illustrated in Figure 13. 

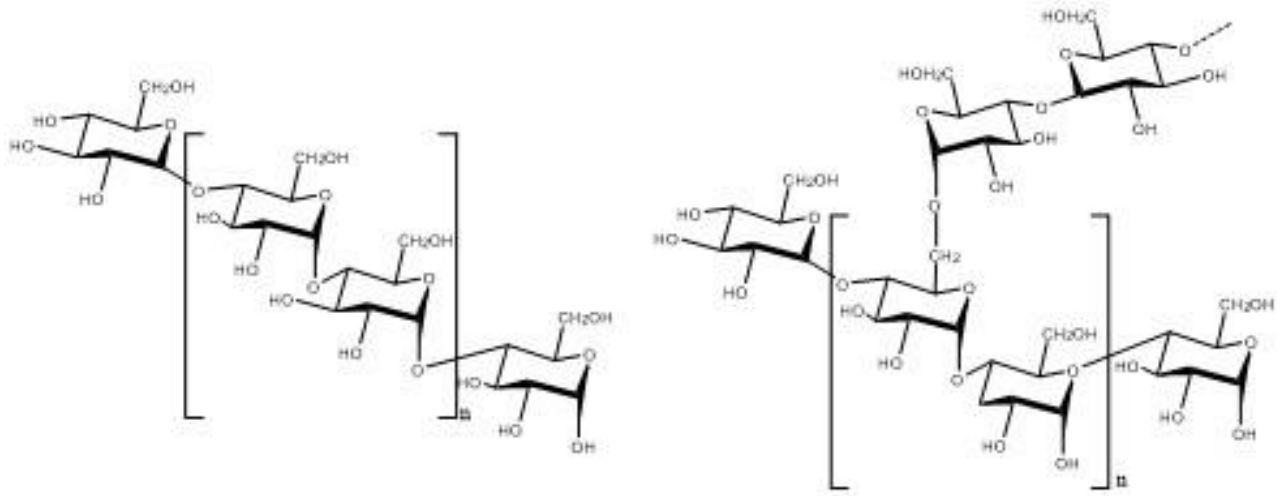

Figure 13 - Chemical structure of (a) amylose and (b) amylopectin.

Starch has been widely used since it comes from low-cost sources and it is capable of being modified or blended into other polymers by improving its processing conditions and properties. Starch has been applied to the manufacture of foams, films, bags, molded items, thermoformed products, and personal hygiene products $[55,56]$.

The dielectric constant and a dielectric loss of starch are 2.900 and 0.303 , respectively [57]. The dielectric properties of starch modified with cellulose and natural rubber latex [58] shows dielectric constant values between 10 and 150, when the frequency and temperature are changed from $10^{3}$ to $10^{6} \mathrm{~Hz}$ and from 30 to $65^{\circ} \mathrm{C}$, respectively. Further, it has been shown that the presence of metal ions (iron, copper, manganese, and calcium) allows to enhance the dielectric constant and dielectric loss of starch to a maximum of 4.4 and 0.72 , respectively.

\subsubsection{Chitin}

Chitin is the second most abundant biopolymer on earth, after cellulose. Chitin is present in many marine organisms, being the most common the shells of crustaceans like crabs and shrimps, and many living organisms naturally synthesize it. Chitin is formed by $\mathrm{N}$-acetylglucosamine chains linked by strong intermolecular $\beta$-(1,4)-glycosidic bonds [60], as shown in Figure 14. Depending on its source, chitin can present $\alpha$ and $\beta$-forms, which are distinguished by strong and weak inter and intramolecular bonds, respectively. 


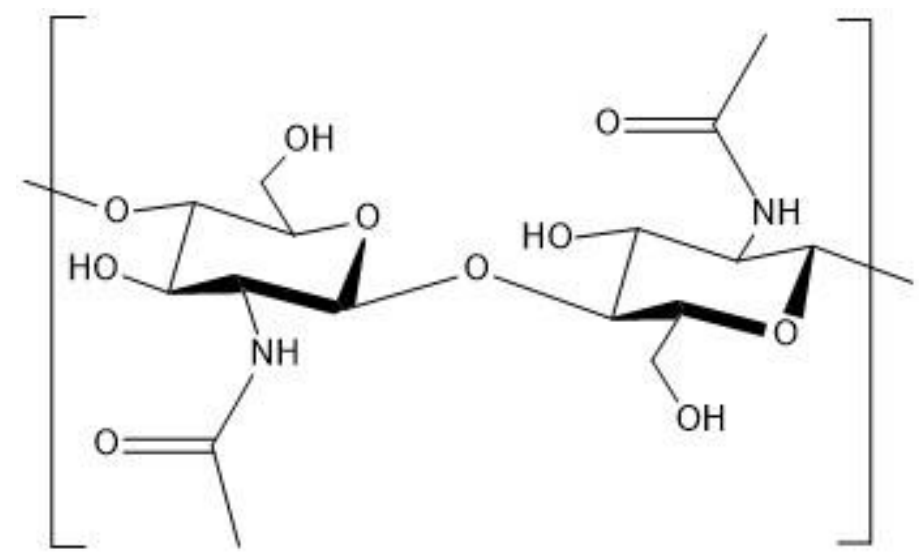

Figure 14 - Chemical structure of chitin.

The biggest problem of chitin is the low solubility in the usual solvents, which is a limitation in its use and processing. To solve this problem, chemical modifications of chitin are used as a pretreatment, leading to a water-soluble anionic polymer. The most common method to improve the solubility of chitin is the complexation with lithium chloride in dimethylacetamide or N-methyl-2-pyrrolidone [61]. Other properties of chitin are the low toxicity, the inertness, and the biodegradability, due to the presence of chitinase. Chitin is used as a wound dressing material, as a periodontal/orthopedic material and for drug delivery systems [60].

The dielectric properties of chitin/cashew gum nanocomposites [62] decreases from 2080 to 2000 with the increase of frequency, from $10^{2}$ to $10^{6} \mathrm{~Hz}$.

\subsubsection{Chitosan}

Chitosan is one of the most abundant polysaccharides in nature. For instance, the crustaceans, mollusks, and insects as well as the fungal cell wall, possess chitosan in the form of chitin. Chitin can be transformed into chitosan through chemical processes such as alkaline deacetylation. Chitosan possesses a linear structure (Figure 15) with Dglucosamine units, and $\mathrm{N}$-acetylglucosamine linked together via $\beta(1-4)$ glycosidic bonds [64]. Additionally, the relative molecular mass of chitosan ranges between 22 and 1800 $\mathrm{kDa}$, with the low relative molecular mass presenting higher solubility and known antimicrobial properties [65]. 
Chitosan is suitable for bioapplications due to the biodegradable, biocompatible, nontoxic, high drug loading ability, mucoadherent, and high charge density properties [66]. Chitosan is generally applied in the scope of wound dressings [67], scaffold [68], drug delivery [69] and as an antimicrobial agent [70].

Chitosan properties are not just unique and interesting for bioapplications; they are also highly dependent on the environmental parameters such as ionic strength, $\mathrm{pH}$ and electric field [71]. In this way, it is possible to tune them to match specific applications requirements.

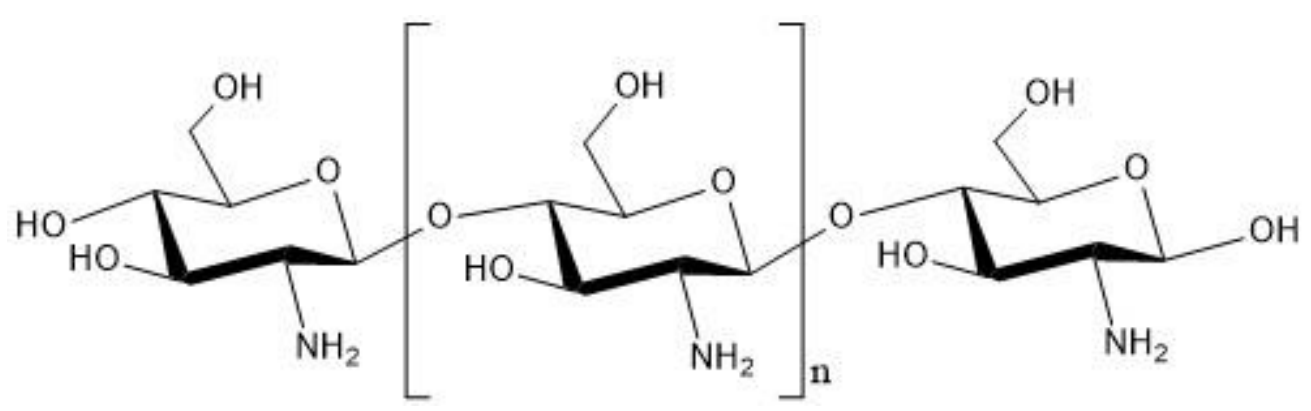

Figure 15 - Scheme of the chemical structure of chitosan.

A few works have addressed the electrical properties of this material. For instance, research has focused on the synthesis and characterization of chitosan/nickel oxide $(\mathrm{NiO})$ thin films as a potential dielectric material [72]. Regarding the pristine chitosan, the results show that the dielectric constant decreases from $\mathrm{xx}$ to $\mathrm{xxx}$ with increasing frequencies - ranging between 0.01 and $100000 \mathrm{~Hz}$. A similar trend was observed for the two chitosan/ $\mathrm{NiO}$ nanocomposite thin films. Further, the authors observed an increase in the dielectric constant from $\mathrm{xx}$ to $\mathrm{xxx}$ with increasing in temperature from $\mathrm{xxx}$ to $\mathrm{xxx}$ (for a fixed frequency), attributed to the higher dipole moments obtained after dipoles rearrangement induced by higher temperatures.

Chitosan-hydroxyapatite (50/50) composites show a dielectric constant that increases with increasing temperature. The maximum dielectric constant, around 561, was obtained at low frequencies $(1 \mathrm{kHz})$ and $75^{\circ} \mathrm{C}$. In contrast, the value of 1.5 was obtained at $1 \mathrm{MHz}$ and $25^{\circ} \mathrm{C}$. The authors also noticed that the $\varepsilon$ measurements for chitosan-hydroxyapatite at body temperature are analogous to the ones from bone tissues [73].

To address the development of new biomaterials researchers have produced chitosan/collagen composites [74]. The studies on the dielectric constant properties revealed that pristine chitosan films present a dielectric constant of $3.94 \mathrm{at} 1 \mathrm{MHz}$. The 
composites with lower concentrations of chitosan and higher amounts of collagen possess lower dielectric constants, ranging between 3.35 and 2.60.

Sebastián Bonardd and co-workers tried to develop a biocomposite that overcomes the typical low dielectric constant of the conventional synthetic polymers (usually between 2 and 4). In this context, chitosan-based composites loaded with nitrile modified cellulose nanocrystals were prepared [75]. The measurements performed at $1 \mathrm{kHz}$ and $25^{\circ} \mathrm{C}$ shown that the dielectric constant increases for larger loadings of cellulose nanocrystals, from 5.5 for pristine chitosan up to 8.5 for the nanocomposite with $50 \mathrm{wt} \%$. The modification of the cellulose nanocrystals with a polarizable group enabled their reorientation, under an electric field, increasing the polarization and the dielectric constant values.

\subsubsection{Collagen}

Collagen is the most abundant structural compound in animals.[76] It consists of three polypeptide chains (Figure 2) with a Glycine-X-Y (where X and Y can be another amino acid residue) that twisted around each other form a triple helix structure [77, 78]. The collagen family possesses several groups of proteins, and until these days, 27 types of collagen are known [78]. The classification of the different collagens is based on their polymeric structures or structural properties [79].

The average amino acid molecular weight in collagen is relatively low because of the high content of the amino acid glycine [80] [81]. The role of glycine in collagen structure is mainly to favor a stable packing between the triple-helix [53]. The most plentiful subfamily of collagen is type I collagen, which is found over all the human body, such as in tendons, skin, cornea, bone, lung, and blood vessel walls [82]. The collagen fibers usually present a remarkable tensile strength and stability; such properties make this molecule valuable towards several applications [80].

As collagen is a very robust molecule, it is frequently used in bone implants [83]. Collagen has also been broadly applied in reconstructive body surgery and as scaffolds for tissue engineering applications [84]. Temperature denatured collagen will produce globular domains and coils, thus becoming gelatine. 


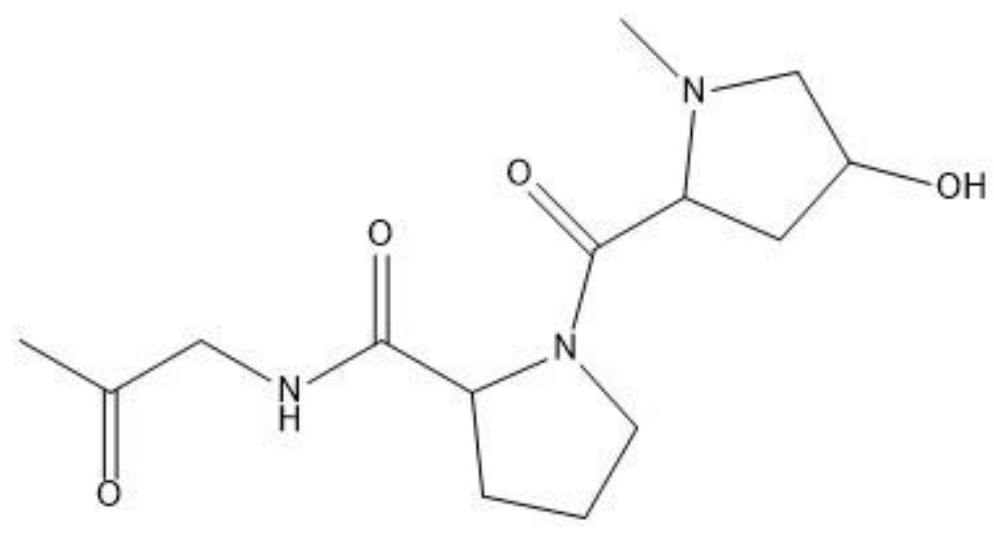

Figure 16 - A schematic representation of the Gly-Pro-Hyp motif found in collagen a-chains.

As collagen is the main protein component of the extracellular matrix and because it is present is almost all human tissues, this protein stands out as a perfect scaffold for tissue engineering [79]. Moreover, collagen also plays a relevant role in the maintenance of the normal structure of tissues [85]. The influence that different collagen cross-linking methodologies has in the dielectric properties of collagen has been addressed, showing that cross-linked and hyaluronic acid grafted collagen presents much higher values of dielectric constants when compared to the unmodified collagen samples. The modified collagen possesses a greater number of charge carriers (protons) increasing the mobility and the dielectric constant [86]. The electric properties of collagen cross-linked with glutaraldehyde (GA) show that at $75^{\circ} \mathrm{C}$ and $500 \mathrm{~Hz}$ the dielectric constant of Col-GA and Col samples are respectively 3.14 and 4.42, as the cross-linking with GA reduces the density of mobile protons in the sample, reducing their polarizability.

Collagen-based blends with different amounts of chitosan [87] show a dielectric constant that increases from $\mathrm{xxx}$ to $\mathrm{xxx}$ with increasing frequency between $100 \mathrm{~Hz}-5 \mathrm{MHz}$, at room temperature. Among the different ratios tested, the Collagen/Chitosan 40\%/60\% and Collagen/Agarose 50\%/50\% possess the highest dielectric constant, respectively around 35 and 60. The authors attribute such results to a putative enhanced dissipation of energy that allowed the thermal activation and higher electron mobility.

An interesting work focused on the production of cultivated collagen to mimic real skin show that the dielectric constant decreases with the increase of frequency. For instance, for the cultivated collagen, the dielectric constant varied between $\approx 16$ and $\approx 1.8$ at 0.1 and $2 \mathrm{THz}$, respectively. Given the results, the authors state that the cultivated collagen 
is not suitable to represent the epidermis dielectric properties (approximately between 6.2 -3.8 for the same frequencies) [88].

\subsubsection{Gum Arabic}

Gum arabic (GA) or acacia gum is a natural biopolymer exudated from the trunks and barks of Acacia senegal and Acacia seyal trees. It is a complex, branched heteropolysaccharide, either neutral or slightly acidic and composed of 1, 3-linked $\beta$-Dgalactopyranosyl units. The side chains of GA are L-arabinose, L-rhamnose, and Dglucuronic acids [90, 91]. The side chains are composed of two to five 1, 3-linked $\beta$-Dgalactopyranosyl units, which join the main chain by 1, 6-linkages. The complex chemical structure of Gum arabic is described in some work as a mixture of polysaccharides and glycoproteins, potassium, magnesium and calcium [91].

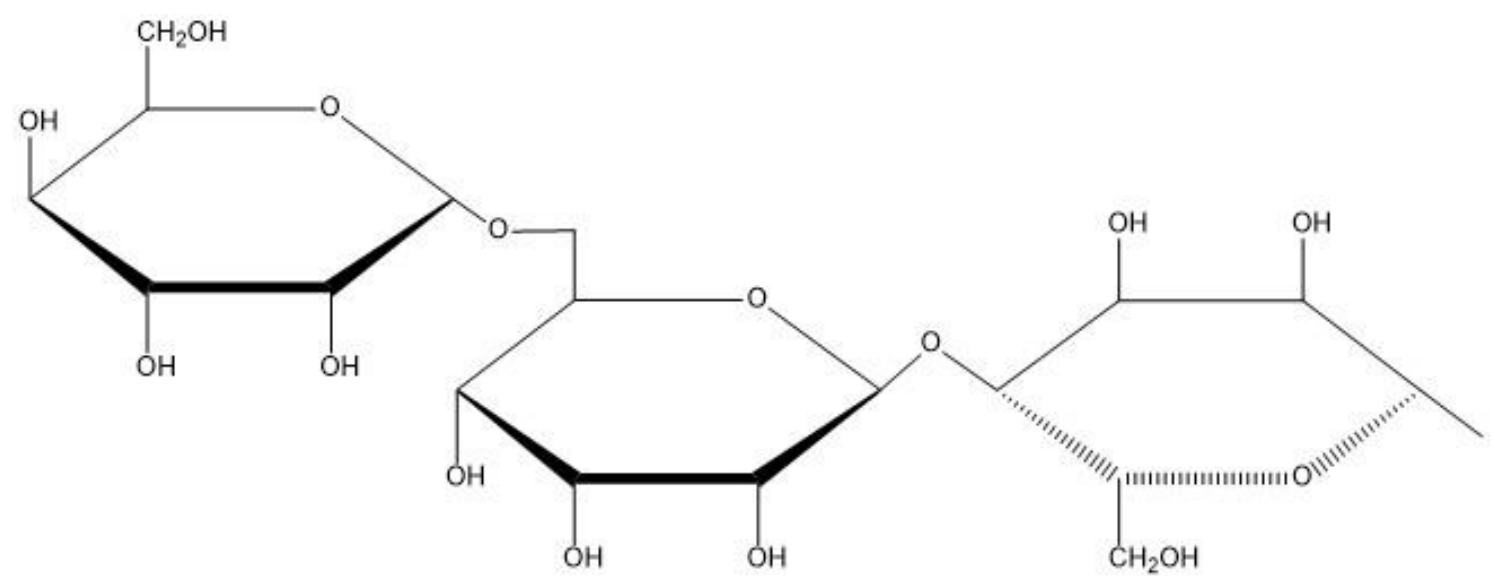

Figure 17 - Representation of the chemical structure of gum arabic.

Once GA is light-weight, biodegradable, biocompatible, flexible and possesses remarkable electrical properties, it has a wide range of applications [92, 93]. One of the most widespread applications of GA is in the food industry, especially because it is tasteless, edible, emulsifier, stabilizer, binder, and shows high water solubility. This biopolymer is incorporated into food formulations, such as ice-creams, candies, soft drinks, beverages, and chewing gums. GA as a food additive allows expanding the shelflife of flavors [94].

GA has been also used in the textile industry to improve the mechanical properties of fibers, and in pharmaceuticals to coat pills [95]. Because of the interesting binding 
properties, GA is also used in lithography [96], printing [97], and paints [98]. More recently, GA has been investigated as a surfactant for nanoparticles [99], nanocomposites [93], and sensors [100].

Having in mind that GA is widely used in food industry, it has been addressed how the permittivity of some hydrocolloids used in the food industry varied with moisture and temperature [101]. The results indicate that the dielectric constant for samples containing GA, performed at $2.45 \mathrm{GHz}$, increases with increasing moisture (ranging between 0 and $20 \%$ ). Further, the dielectric constant increases with increasing temperature over the range $20^{\circ} \mathrm{C}$ to $100^{\circ} \mathrm{C}$, this dependence being more evident under higher contents of GA. The higher dielectric value, around 4.8 was obtained at $100^{\circ} \mathrm{C}$ and $20 \%$ moisture content. Gum Arabic/carbon black nanocomposites show a dielectric constant of xxxx that decreases with increasing frequencies and carbon black loading [102].

Gum Arabic-Cadmium Sulphide (CdS) nanocomposites show an increases of the dielectric constant with filler content [103] from $\mathrm{xx}$ for pure GA to a maximum of XXX for $10 \%$ of CdS.

In another work, the dielectric constant of gum Arabic/Zinc oxide $(\mathrm{ZnO})$ nanocomposites was analyzed (at $2 \mathrm{kHz}$ ), and a significant increase was observed when semiconducting nanoparticles were incorporated as a filler. The authors also found that the temperature significantly influenced the dielectric constant, being the highest value (275) obtained at $\approx 70^{\circ} \mathrm{C}$, for the sample containing $10 \% \mathrm{ZnO}$ [92].

\subsubsection{Silk}

Silks are protein polymers that are naturally spun into fibers by some insects as silkworms, spiders, but scorpions. Some mite larvae and fly are also silk producers [104, 105]. As a natural structural protein, silk can be used as shelters (in the form of cocoons during their development). Spiders use the silk fibers to capture insects, to obtain structural support, and to evade from predators, among others [106-108].

Silk fibers, just like the previously presented biopolymers, are non-toxic, biocompatible, and biodegradable [109]. In addition, silk possesses extraordinary mechanical properties (e.g., tensile strength, toughness, elasticity) [110] and the possibility of genetic tailoring the structure [104]. Among a broad types of silks, silk fibroin (SF) (Figure 18) constitutes the protein that produces the filaments of silkworm silk [111]. 


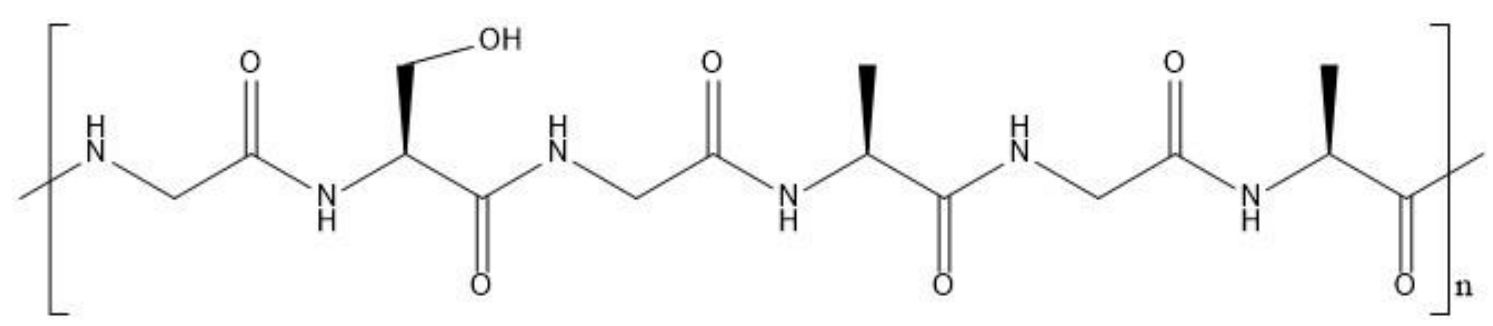

Figure 18 - Representation of the chemical structure of silk fibroin.

Fibroin constitutes approximately 70 to $80 \mathrm{wt} \%$ of silk content (the remaining part is sericin and waxes), depending on their origin and culture conditions [112, 113]. Silk fibroin presents high processability, which allows to easily produce different morphologies, such as mats, thin films, microplates, and needles [111, 114].

There is a large variety of applications for silk-based materials, for instance in the textile industry [115], tissue engineering [116], scaffolds [117], drug delivery[118], biosensors, optics, and many others [114, 119].

Concerning silk fibroin, few works have focused on the electrical properties of silk. For instance, SF thin films were produced and $\gamma$-irradiated [120], showing that higher $\gamma$ irradiation doses also increase the dielectric constant towards the pure SF film. The higher dielectric constant, around 6.5, was obtained at $3.5 \mathrm{eV}$ for the sample pre-irradiated with $300 \mathrm{kGy}$, which corresponds to relatively high values when compared with the lower dielectric constant of non-irradiated SF films, around 3.5.

The dielectric constant of silk fibroin films decreases with the crystallization time and with increasing frequency $(20 \mathrm{~Hz}$ to $1 \mathrm{MHz})$. At $20 \mathrm{~Hz}$ and the initial time of the crystallization process the dielectric constant is $\approx 26$, and 45 minutes later the value decreased to $\approx 10$. Such results are caused by the transition from $\alpha$-helices to $\beta$-sheets that occur during the crystallization process. The antiparallel $\beta$-sheets, without a net dipole moment, reduces the number of effective dipole moments, which will contribute to the reduction of the dielectric constant during the crystallization process [122].

\section{Synthetic polymers}

Synthetic polymers can be divided in different types as is shown in Figure 19 taking into account the polymerization type. 


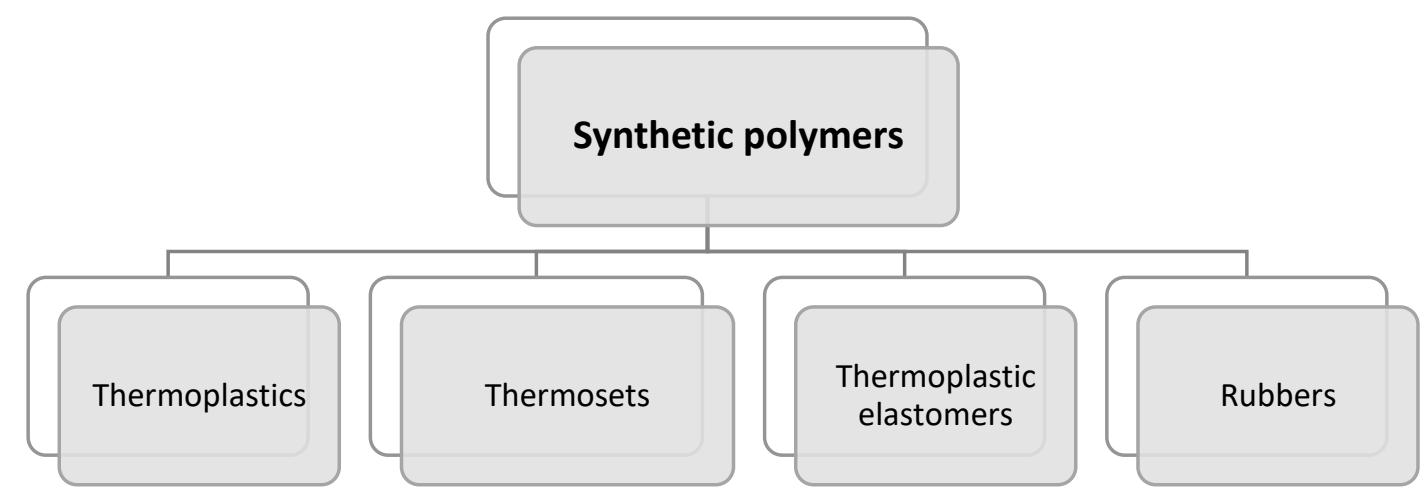

Figure 19 - Different types of the synthetic polymers.

Synthetic polymers are most commonly used in dielectric applications from high voltage direct current (HVDC) cables to film capacitors and the most prominent are acrylonitrilebutadiene-styrene (ABS), Poly(vinyl chloride) (PVC), Poly(methyl methacrylate) (PMMA), Poly(acrylonitrile) (PAN), Poly(ethylene terephthalate) (PET), Poly(carbonate) (PC), Poly(ethylene) (PE), Poly(tetrafluoroethylene) (PTFE) and Poly(vinylidene fluoride) (PVDF), the chemical structure for these polymers being shown in figure 20 .
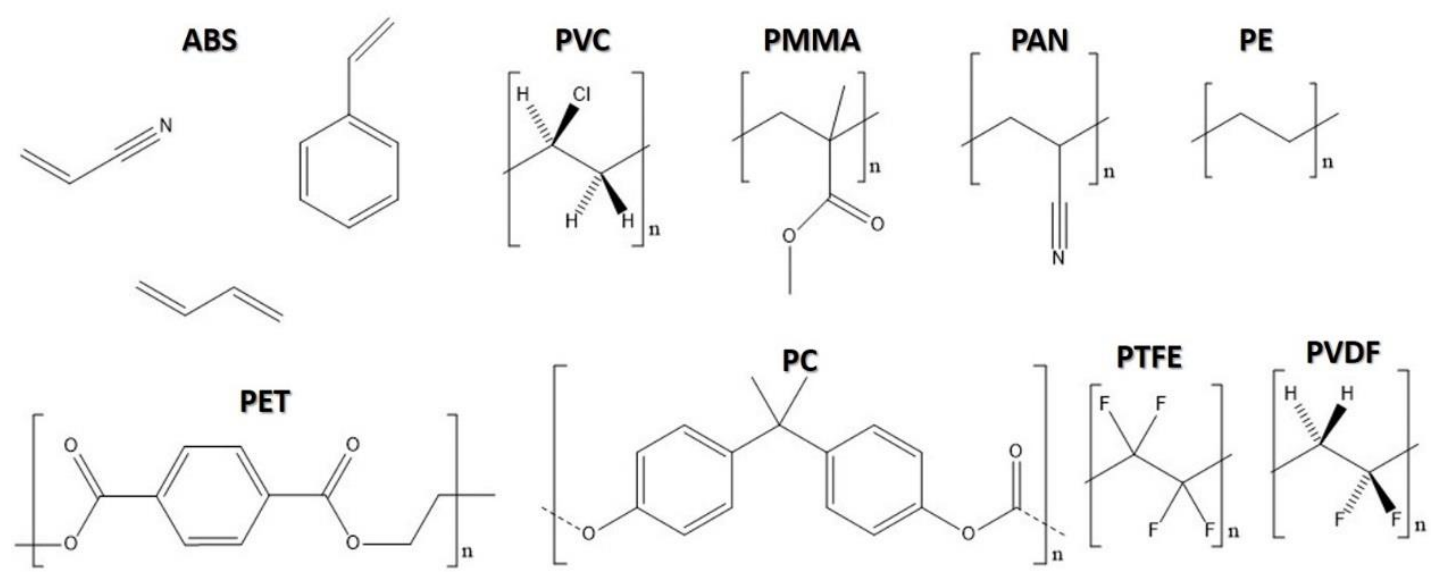

Figure 20 - Chemical structure of some synthetic polymers.

PVDF polymer stands out in comparison to the other polymers due to its high dielectric constant ( $\varepsilon=7-10)$, the structure of the polymers determining its dielectric constant value 
$[123,124]$. For other polymers, the dielectric constant is between 2 to 5 as is shown in the table 1 .

Table 2 - Dielectric constant and losses for several synthetic polymers at room temperature.

\begin{tabular}{|c|c|c|}
\hline Polymer & Dielectric constant & Ref \\
\hline ABS & $\sim 2-3$ & {$[125]$} \\
\hline PVC & $\sim 3-5$ & {$[126]$} \\
\hline PMMA & $\sim 2$ & {$[127]$} \\
\hline PAN & $\sim 2-3$ & {$[128]$} \\
\hline PE & $\sim 2.5$ & {$[129,130]$} \\
\hline PET & $\sim 1.5-2.5$ & {$[131]$} \\
\hline PC & $\sim 2-4$ & {$[132]$} \\
\hline PTFE & $\sim 2$ & {$[133]$} \\
\hline PVDF & $\sim 7-10$ & {$[134]$} \\
\hline
\end{tabular}

Typically, to improve the dielectric constant of ABS, polymer composites are prepared with various fillers, such as, $\mathrm{BaTiO} 3$ [135], nanoclay [125], graphene nanoplatelets and multiwall carbon nanotubes [136], palm fiber [137] and $\mathrm{Ba}_{0.6} \mathrm{Sr}_{0.4} \mathrm{TiO}_{3}$ [138], the dielectric constant increasing more than $100 \%$, depending on the filler concentration. The approach of tailoring the dielectric response of synthetic polymers by the development of polymer composites is a general approach and has been also used for PVDF, PMMA, PET, PC and PAN, among others.

The dielectric constant and loss factor of poly(vinyl chloride) (PVC) over a wide range of temperature and frequency was analysed [139] and was observed an maximum in dielectric loss that corresponding to the glass transition temperature. The dielectric properties of this polymer are very sensitive to thermal pretreatment [139].

The dielectric behaviour of PMMA shows diverse relaxation process in which the $\alpha$ relaxation is related to the glass transition of PMMA and corresponds to the rotation of lateral groups around the main-chain axis [127]. Also for this polymer, it is present a $\beta$ relaxation related to the partial rotation of the $-\mathrm{COOCH}_{3}$ side groups around the $\mathrm{C}-\mathrm{C}$ bonds linking these side groups to the main chain [140].

$\mathrm{PE}$ is a semicristalline polymer with a dielectric constant value of $\sim 2.5$ and its value increases with increasing frequency due to DC conductivity [129]. However, its dielectric behavior depends on the measurements being carried out under dry or humid environments [141], as well as on the molecular weight [142]. 
For the PVDF polymer, the dielectric constant value depends on the crystalline phase of the polymer, the polar $\beta$ phase showing the highest dielectric constant value compared to other phases [143].

\section{Conclusions}

Considering the rapid advances in several applications that involve dielectric materials, the evaluation of the dielectric response of polymers and understanding the physical phenomena associated it is essential for increasing the performance and efficiency of the device.

Synthetic polymers are the most used for electrical applications and PVDF based polymers stand out compared to other polymers due to their high dielectric constant value. Some natural polymers show dielectric constants larger than 5 but the main problem of these polymers is their hydrophilic nature, large losses and the variation over time.

Scientific efforts are still needed to understand and tailor the dielectric behavior of natural polymers in order to substitute the synthetic polymers into many applications.

\section{Acknowledgments}

The authors thank the FCT (Fundação para a Ciência e Tecnologia) for financial support under the framework of Strategic Funding grants UID/FIS/04650/2013, UID/EEA/04436/2013; and project no. PTDC/FIS-MAC/28157/2017. The authors also thank the FCT for financial support under grants SFRH/BD/122373/2016 (H.S.) SFRH/BD/98616/2013 (P.M.M.) and SFRH/BPD/112547/2015 (C.M.C.). Financial support from the Basque Government under the ELKARTEK, HAZITEK and PIBA (PIBA-2018-06) programs is also acknowledged.

\section{References}

1. $\quad$ Ellis, B. and R. Smith, Polymers: A Property Database, Second Edition. 2008: CRC Press.

2. Blythe, A.R., T. Blythe, and D. Bloor, Electrical Properties of Polymers. 2005: Cambridge University Press.

3. Sillars, R.W., The properties of a dielectric containing semiconducting particles of various shapes. Institution of Electrical Engineers - Proceedings of the Wireless Section of the Institution, 1937. 12(35): p. 139-155.

4. Furukawa, T., K. Yasuda, and Y. Takahashi, Dielectric and conductive spectra of the composite of barium titanate and LiClO/sub 4/-doped polyethylene oxide. IEEE Transactions on Dielectrics and Electrical Insulation, 2004. 11(1): p. 65-71.

5. Kremer, F. and A. Schönhals, Broadband Dielectric Spectroscopy. 2012: Springer Berlin Heidelberg. 
6. Havriliak Jr., S. and S.J. Havriliak, A rigorous comparison of theoretical autocorrelation functions with dielectric relaxation parameters for the alpha process of polymers. Journal of Polymer Science Part B: Polymer Physics, 1997. 35(12): p. 1887-1897.

7. Barringer, S.A., et al., The dielectric properties of whey protein as indicators of change in polymer mobility. Topics in Catalysis, 1995. 9(4): p. 343-348.

8. Bibi, F., et al., A review: Origins of the dielectric properties of proteins and potential development as bio-sensors. Sensors (Switzerland), 2016. 16(8).

9. Castro-Giráldez, M., P.J. Fito, and P. Fito, Application of microwaves dielectric spectroscopy for controlling pork meat (Longissimus dorsi) salting process. Journal of Food Engineering, 2010. 97(4): p. 484-490.

10. Ahmed, J., H.S. Ramaswamy, and V.G.S. Raghavan, Dynamic viscoelastic, calorimetric and dielectric characteristics of wheat protein isolates. Journal of Cereal Science, 2008. 47(3): p. 417-428.

11. John, M.J. and S. Thomas, Natural polymers: An overview, in RSC Green Chemistry. 2012. p. 1-7.

12. John, M.J. and S. Thomas, Biofibres and biocomposites. Carbohydrate Polymers, 2008. 71(3): p. 343-364.

13. Ali, A. and S. Ahmed, Natural polymers: An overview, in Natural Polymers: Derivatives, Blends and Composites, Volume I. 2016. p. 1-22.

14. Avérous, L., Biodegradable Multiphase Systems Based on Plasticized Starch: A Review. Journal of Macromolecular Science, Part C, 2004. 44(3): p. 231-274.

15. Gopinath, V., et al., A review of natural polysaccharides for drug delivery applications: Special focus on cellulose, starch and glycogen. Biomedicine and Pharmacotherapy, 2018. 107: p. 96-108.

16. Morán, J.I., L.N. Ludueña, and V.A. Alvarez, Recent Advances in Nanocomposites Based on Biodegradable Polymers and Nanocellulose, in Nanocellulose Polymer Nanocomposites: Fundamentals and Applications. 2014. p. 237-254.

17. Sudhakar, Y.N., M. Selvakumar, and D. Krishna Bhat, Lithium salts doped biodegradable gel polymer electrolytes for supercapacitor application. Journal of Materials and Environmental Science, 2015. 6(5): p. 1218-1227.

18. Lazzari, A., P. Kleinebudde, and K. Knop, Xanthan gum as a rate-controlling polymer for the development of alcohol resistant matrix tablets and mini-tablets. International Journal of Pharmaceutics, 2018. 536(1): p. 440-449.

19. Turabi, E., et al., Dielectric and thermal properties of rice cake formulations containing different gums types. International Journal of Food Properties, 2010. 13(6): p. 1199-1206.

20. Keskin, S.O., G. Sumnu, and S. Sahin, A study on the effects of different gums on dielectric properties and quality of breads baked in infrared-microwave combination oven. European Food Research and Technology, 2007. 224(3): p. 329-334.

21. Zhu, D., et al., Thermal and dielectric investigations on the blends of $\kappa$ carrageenan and nano-structured polyaniline. Synthetic Metals, 2014. 187(1): p. 165-171.

22. Tsubaki, S., et al., Effects of acidic functional groups on dielectric properties of sodium alginates and carrageenans in water. Carbohydrate Polymers, 2015. 115: p. 78-87.

23. Cherian, B., et al., Protein-based Polymer Nanocomposites for Regenerative Medicine. 2012. p. 255. 
24. Ge, L., et al., Biomaterial Gelatin Film Based Crossbar Structure Resistive Switching Devices. IEEE Transactions on Nanotechnology, 2018. 17(1): p. 78-83.

25. Young, S., et al., Gelatin as a delivery vehicle for the controlled release of bioactive molecules. J Control Release, 2005. 109(1-3): p. 256-74.

26. Altarawneh, M.M., G.A. Alharazneh, and O.Y. Al-Madanat, Dielectric properties of single wall carbon nanotubes-based gelatin phantoms. Journal of Advanced Dielectrics, 2018. 8(2).

27. Landi, G., H.C. Neitzert, and A. Sorrentino. Temperature-dependent dielectric properties of a thermoplastic gelatin. in AIP Conference Proceedings. 2016.

28. Said, M.S.M., et al. Investigation on dielectric properties in gelatin-based phantom for human brain. in ISAP 2014 - 2014 International Symposium on Antennas and Propagation, Conference Proceedings. 2015.

29. Masood, R. and M. Miraftab, Psyllium: Current and Future Applications, in Medical and Healthcare Textiles, S.C. Anand, et al., Editors. 2010, Woodhead Publishing. p. 244-253.

30. Boussatour, G., et al., Dielectric Characterization of Polylactic Acid Substrate in the Frequency Band 0.5-67 GHz. IEEE Microwave and Wireless Components Letters, 2018. 28(5): p. 374-376.

31. Su, Y.-H., et al., High aspect ratio nanoimprinted grooves of poly(lactic-coglycolic acid) control the length and direction of retraction fibers during fibroblast cell division. Vol. 10. 2015. 041008.

32. Haroon, S. Ullah, and J.A. Flint. Electro-textile based wearable patch antenna on biodegradable poly lactic acid (PLA) plastic substrate for $2.45 \mathrm{GHz}$, ISM band applications. in 2014 International Conference on Emerging Technologies (ICET). 2014.

33. Luo, M., et al., A Microfabricated Wireless RF Pressure Sensor Made Completely of Biodegradable Materials. Journal of Microelectromechanical Systems, 2014. 23(1): p. 4-13.

34. Géczy, A., et al. Low temperature soldering on biopolymer (PLA) Printed Wiring Board substrate. in Proceedings of the 2011 34th International Spring Seminar on Electronics Technology (ISSE). 2011.

35. Reyes, N., et al., Complex Dielectric Permittivity of Engineering and 3D-Printing Polymers at Q-Band. Journal of Infrared, Millimeter, and Terahertz Waves, 2018. 39(11): p. 1140-1147.

36. Dichtl, C., P. Sippel, and S. Krohns, Dielectric Properties of 3D Printed Polylactic Acid. Advances in Materials Science and Engineering, 2017. 2017: p. 10.

37. Meraldo, A., Introduction to Bio-Based Polymers, in Multilayer Flexible Packaging: Second Edition. 2016. p. 47-52.

38. Fadzil, F.I.B.M. and T. Tsuge, Bioproduction of polyhydroxyalkanoate from plant oils, in Microbial Applications. 2017. p. 231-260.

39. Brigham, C., Biopolymers: Biodegradable Alternatives to Traditional Plastics, in Green Chemistry: An Inclusive Approach. 2017. p. 753-770.

40. Petrović, Z.S., et al., A chemical route to high molecular weight vegetable oilbased polyhydroxyalkanoate. Macromolecules, 2010. 43(9): p. 4120-4125.

41. Belyaev, B.A., et al., Permittivity of polyhydroxyalkanoate biopolymer solutions. Russian Physics Journal, 2002. 45(4): p. 394-399.

42. Habib Ullah, M., W.N.L. Mahadi, and T.A. Latef, Aerogel Poly(butylene succinate) Biomaterial Substrate for RF and Microwave Applications. Scientific Reports, 2015. 5. 
43. Hirai, N., H. Ishikawa, and Y. Ohki. Electrical conduction properties of several biodegradable polymers. in Annual Report - Conference on Electrical Insulation and Dielectric Phenomena, CEIDP. 2007.

44. Tai, H.J., Dielectric spectroscopy of poly(butylene succinate) films. Polymer, 2007. 48(15): p. 4558-4566.

45. Choi, K., et al., Cellulose-based smart fluids under applied electric fields. Materials, 2017. 10(9).

46. Pleumphon, C., et al., Development of conductive bacterial cellulose composites: An approach to bio-based substrates for solar cells. Journal of Biobased Materials and Bioenergy, 2017. 11(4): p. 321-329.

47. Srasri, K., et al., Recovery potential of cellulose fiber from newspaper waste: An approach on magnetic cellulose aerogel for dye adsorption material. International Journal of Biological Macromolecules, 2018. 119: p. 662-668.

48. Wang, B., et al., Preparation and dielectric properties of porous cyanoethyl cellulose membranes. Cellulose, 2018.

49. Qin, Y., et al., Applications of Alginate as a Functional Food Ingredient, in Biopolymers for Food Design. 2018. p. 409-429.

50. Bekin, S., et al., Dielectric, thermal, and swelling properties of calcium ioncrosslinked sodium alginate film. Polymer Engineering and Science, 2014. 54(6): p. 1372-1382.

51. Galiano, F., et al., Advances in biopolymer-based membrane preparation and applications. Journal of Membrane Science, 2018. 564: p. 562-586.

52. Matsumiya, Y., et al., Dielectric behavior of cis-polyisoprene in carbon dioxide under high pressure. Nihon Reoroji Gakkaishi, 2007. 35(3): p. 155-162.

53. Syugaev, A.V., et al., Chemical modification of $\mathrm{Fe}$ powders under surfactantassisted ball milling in polydiene solutions. Colloids and Surfaces A: Physicochemical and Engineering Aspects, 2018. 540: p. 53-66.

54. Belgacem, M.N. and A. Gandini, Monomers, Polymers and Composites from Renewable Resources. Monomers, Polymers and Composites from Renewable Resources. 2008.

55. Mohanty, A.K., M. Misra, and L.T. Drzal, Natural fibers, biopolymers, and biocomposites. Natural Fibers, Biopolymers, and Biocomposites. 2005. 1-877.

56. Mehta, A., K.K. Bhardwaj, and R. Gupta, Biodegradable polymers for industrial applications, in Green Polymeric Materials: Advances and Sustainable Development. 2017. p. 123-146.

57. Mohamad, S.N.H., et al., Dielectric properties for selected wall material in the development of microwave-encapsulation-drying. Journal of Food Science and Technology, 2018. 55(12): p. 5161-5165.

58. Drakopoulos, S.X., et al., Thermoplastic starch modified with microfibrillated cellulose and natural rubber latex: A broadband dielectric spectroscopy study. Carbohydrate Polymers, 2017. 157: p. 711-718.

59. Fan, D.M., et al., The influence of metal ions on the dielectric enhancement and radical generation of rice starch during microwave processing. International Journal of Biological Macromolecules, 2017. 94: p. 266-270.

60. Wasupalli, G.K. and D. Verma, Polysaccharides as biomaterials, in Fundamental Biomaterials: Polymers. 2018. p. 37-70.

61. Duarte, A.R., S.S. Silva, and R.L. Reis, Chitin/Chitosan Based Aerogels: Processing and Morphology, in RSC Green Chemistry. 2018. p. 9-24. 
62. Ramesan, M.T., et al., Influence of magnetite nanoparticles on electrical, magnetic and thermal properties of chitin/cashew gum biopolymer nanocomposites. Polymer Composites, 2018. 39: p. E540-E549.

63. Ramesan, M.T., et al., Effect of Silver Doped Zinc Oxide as Nanofiller for the Development of Biopolymer Nanocomposites from Chitin and Cashew Gum. Journal of Polymers and the Environment, 2018. 26(7): p. 2983-2991.

64. Jiao, J., J. Huang, and Z. Zhang, Hydrogels based on chitosan in tissue regeneration: How do they work? A mini review. Journal of Applied Polymer Science, 2019. 136(13).

65. Bano, I., et al., Chitosan: A potential biopolymer for wound management. International Journal of Biological Macromolecules, 2017. 102: p. 380-383.

66. Pulicharla, R., et al., Encapsulation and release studies of strawberry polyphenols in biodegradable chitosan nanoformulation. International Journal of Biological Macromolecules, 2016. 88: p. 171-178.

67. Vasile, B.S., et al., Synthesis and characterization of a novel controlled release zinc oxide/gentamicin-chitosan composite with potential applications in wounds care. International Journal of Pharmaceutics, 2014. 463(2): p. 161-169.

68. Qu, C., et al., A thermosensitive RGD-modified hydroxybutyl chitosan hydrogel as a $3 D$ scaffold for BMSCs culture on keloid treatment. International Journal of Biological Macromolecules, 2019. 125: p. 78-86.

69. Mahmoodzadeh, F., B. Jannat, and M. Ghorbani, Chitosan-based nanomicelle as a novel platform for targeted delivery of methotrexate. International Journal of Biological Macromolecules, 2019. 126: p. 517-524.

70. Arancibia, M.Y., et al., Antimicrobial and antioxidant chitosan solutions enriched with active shrimp (Litopenaeus vannamei) waste materials. Food Hydrocolloids, 2014. 35: p. 710-717.

71. Fernandes, S.C.M., et al., Transparent chitosan films reinforced with a high content of nanofibrillated cellulose. Carbohydrate Polymers, 2010. 81(2): p. 394401.

72. Bhatt, A.S., et al., Chitosan/NiO nanocomposites: A potential new dielectric material. Journal of Materials Chemistry, 2011. 21(35): p. 13490-13497.

73. Petrov, I., et al., Dielectric and electric properties of new chitosan-hydroxyapatite materials for biomedical application: Dielectric spectroscopy and corona treatment. Carbohydrate Polymers, 2016. 151: p. 770-778.

74. Lima, C.G.A., et al., DC conductivity and dielectric permittivity of collagenchitosan films. Materials Chemistry and Physics, 2006. 99(2): p. 284-288.

75. Bonardd, S., et al., Biocomposites with increased dielectric constant based on chitosan and nitrile-modified cellulose nanocrystals. Carbohydr Polym, 2018. 199: p. 20-30.

76. Hulmes, D.J.S., Collagen Diversity, Synthesis and Assembly, in Collagen: Structure and Mechanics, P. Fratzl, Editor. 2008, Springer US: Boston, MA. p. 15-47.

77. Rita, B., et al., Recent Progress on Collagen Triple Helix Structure, Stability and Assembly. Protein \& Peptide Letters, 2002. 9(2): p. 107-116.

78. Yu, S.M., Y. Li, and D. Kim, Collagen mimetic peptides: Progress towards functional applications. Soft Matter, 2011. 7(18): p. 7927-7938.

79. Yang, C., et al., The application of recombinant human collagen in tissue engineering. BioDrugs, 2004. 18(2): p. 103-119.

80. Liu, D., et al., Collagen and Gelatin. Annual Review of Food Science and Technology, 2015. 6(1): p. 527-557. 
81. Subhan, F., et al., Marine Collagen: An Emerging Player in Biomedical applications. J Food Sci Technol, 2015. 52(8): p. 4703-7.

82. Silver, F.H. and M. Jaffe, 7 - Structure and behavior of collagen fibers, in Handbook of Tensile Properties of Textile and Technical Fibres, A.R. Bunsell, Editor. 2009, Woodhead Publishing. p. 179-193.

83. Cunniffe, G.M. and F.J. O'Brien, Collagen scaffolds for orthopedic regenerative medicine. JOM, 2011. 63(4): p. 66.

84. Oliveira, S.M., et al., An improved collagen scaffold for skeletal regeneration. Journal of biomedical materials research. Part A, 2010. 94(2): p. 371-379.

85. Brown, J.C. and R. Timpl, The Collagen Superfamily. International Archives of Allergy and Immunology, 1995. 107(4): p. 484-490.

86. Marzec, E. and K. Pietrucha, The effect of different methods of cross-linking of collagen on its dielectric properties. Biophysical Chemistry, 2008. 132(2): p. 8996.

87. Abdel Aziz Mahmoud, et al., Dielectric Spectroscopy Measurements on Collagen Blends. Middle East Journal of Applied Sciences, 2015. 05(05): p. 94-106.

88. Yang, K., et al. Dielectric constant measurement of collagen at terahertz band using terahertz time domain spectroscopy. in 2017 IEEE International Symposium on Antennas and Propagation \& USNC/URSI National Radio Science Meeting. 2017.

89. Dhia, Dielectric Properties of Collagen on Plasma Modified Polyvinylidene Fluoride. Vol. 9. 2012. 694-699.

90. Shirwaikar, A., et al., Herbal excipients in novel drug delivery systems. Indian journal of pharmaceutical sciences, 2008. 70(4): p. 415-422.

91. Sukhotu, R., et al., Changes in physiochemical properties and stability of peanut oil body emulsions by applying gum arabic. LWT - Food Science and Technology, 2016. 68: p. 432-438.

92. Barik, P., A. Bhattacharjee, and M. Roy, Preparation, characterization and electrical study of gum arabic/ZnO nanocomposites. Bulletin of Materials Science, 2015. 38(6): p. 1609-1616.

93. Bhakat, D., P. Barik, and A. Bhattacharjee, Electrical conductivity behavior of Gum Arabic biopolymer-Fe3O4 nanocomposites. Journal of Physics and Chemistry of Solids, 2018. 112: p. 73-79.

94. Anderson, D.M.W. and M.A. Eastwood, The safety of gum arabic as a food additive and its Energy Value as an ingredient: a brief review. Journal of Human Nutrition and Dietetics, 1989. 2(3): p. 137-144.

95. Patel, S. and A. Goyal, Applications of Natural Polymer Gum Arabic: A Review. International Journal of Food Properties, 2015. 18(5): p. 986-998.

96. Hohne, D.N., et al., Near-surface structure of lithographic ink-fountain solution emulsions on model substrates. Colloids and Surfaces A: Physicochemical and Engineering Aspects, 2008. 326(3): p. 138-146.

97. Slade, S., THERMOCHROMIC PAINTS AND PRINTING INKS. Engineering digest Toronto, 1987. 33(2): p. 24-25.

98. Sano, N. and P.J. Cumpson, Surface analysis characterisation of gum binders used in modern watercolour paints. Applied Surface Science, 2016. 364: p. 870877.

99. Li, Y.F., et al., Hydrothermal synthesis of silver nanoparticles in Arabic gum aqueous solutions. Transactions of Nonferrous Metals Society of China (English Edition), 2015. 25(6): p. 2081-2086. 
100. Tiwari, A., Gum Arabic-Graft-Polyaniline: An Electrically Active Redox Biomaterial for Sensor Applications. Journal of Macromolecular Science, Part A, 2007. 44(7): p. 735-745.

101. Nelson, S., A. Prakash, and K. Lawrence, Moisture and Temperature Dependence of the Permittivities of Some Hydrocolloids at 2.45 GHZ. Journal of Microwave Power and Electromagnetic Energy, 1991. 26(3): p. 178-185.

102. Elhadi, A., et al., Determination of Dielectric Constant of Gum Arabic / Carbon Black Composite Material. Vol. 3. 2015. 1-71.

103. Barik, P., A. Bhattacharjee, and M. Roy, Dielectric properties of Gum ArabicCdS nanocomposites. 2012.

104. Altman, G.H., et al., Silk-based biomaterials. Biomaterials, 2003. 24(3): p. 401416.

105. Tokareva, O., et al., Recombinant DNA production of spider silk proteins. Microbial biotechnology, 2013. 6(6): p. 651-663.

106. Hardy, J.G., L.M. Römer, and T.R. Scheibel, Polymeric materials based on silk proteins. JPOL Polymer, 2008. 49(20): p. 4309-4327.

107. Vepari, C. and D.L. Kaplan, Silk as a Biomaterial. Progress in polymer science, 2007. 32(8-9): p. 991-1007.

108. Hardy, J.G. and T.R. Scheibel, Composite materials based on silk proteins. Progress in Polymer Science, 2010. 35(9): p. 1093-1115.

109. Hakimi, O., et al., Spider and mulberry silkworm silks as compatible biomaterials. Composites Part B: Engineering, 2007. 38(3): p. 324-337.

110. Schoeser, M., Silk. 2007, New Haven, Conn.; London: Yale University Press ;.

111. Brito-Pereira, R., et al., Silk fibroin-magnetic hybrid composite electrospun fibers for tissue engineering applications. Composites Part B: Engineering, 2018. 141: p. 70-75.

112. Parmal, B.P.A., Mary Schoeser, Silk. Winterthur Portfolio, 2008. 42(4): p. 292293.

113. Cheung, H.-y., et al., Natural fibre-reinforced composites for bioengineering and environmental engineering applications. Composites Part B: Engineering, 2009. 40(7): p. 655-663.

114. Koh, L.D., et al., Structures, mechanical properties and applications of silk fibroin materials. Progress in Polymer Science, 2015. 46: p. 86-110.

115. Bhardwaj, N. and S.C. Kundu, Electrospinning: A fascinating fiber fabrication technique. Biotechnology Advances, 2010. 28(3): p. 325-347.

116. Drury, J.L. and D.J. Mooney, Hydrogels for tissue engineering: scaffold design variables and applications. Biomaterials, 2003. 24(24): p. 4337-4351.

117. Unger, R.E., et al., Endothelialization of a non-woven silk fibroin net for use in tissue engineering: growth and gene regulation of human endothelial cells. Biomaterials, 2004. 25(21): p. 5137-5146.

118. Numata, K. and D.L. Kaplan, Silk-Based Gene Carriers with Cell Membrane Destabilizing Peptides. Biomacromolecules, 2010. 11(11): p. 3189-3195.

119. Freddi, G., M. Tsukada, and S. Beretta, Structure and physical properties of silk fibroin/polyacrylamide blend films. Journal of Applied Polymer Science, 1999. 71(10): p. 1563-1571.

120. Madhukumar, R., et al., Optical properties of $\gamma$-irradiated Bombyx mori silk fibroin films. Radiation Effects and Defects in Solids, 2015. 170(11): p. 906-915.

121. Asha, S., Y. Sangappa, and G. Sanjeev, Optical properties of electron irradiated Bombyx mori silk fibroin films. Journal of Optics, 2016. 45(1): p. 66-72. 
122. Yu, L., et al., Dielectric Relaxation Spectroscopy of Hydrated and Dehydrated Silk Fibroin Cast from Aqueous Solution. Biomacromolecules, 2010. 11(10): p. 2766-2775.

123. Baer, E. and L. Zhu, 50th Anniversary Perspective: Dielectric Phenomena in Polymers and Multilayered Dielectric Films. Macromolecules, 2017. 50(6): p. 2239-2256.

124. Wang, W., J. Yang, and Z. Liu, Dielectric and energy storage properties of PVDF films with large area prepared by solution tape casting process. IEEE Transactions on Dielectrics and Electrical Insulation, 2017. 24(2): p. 697-703.

125. Jain, P.K., 3D printed polymer dielectric substrates with enhanced permittivity by nanoclay inclusion AU - Francis, Vishal. Virtual and Physical Prototyping, 2017. 12(2): p. 107-115.

126. Fitzgerald, E.R. and R.F. Miller, Dielectric properties of the system polyvinyl chloride-dimethylthianthrene. Journal of Colloid Science, 1953. 8(1): p. 148-169.

127. Bistac, S. and J. Schultz, Study of solution-cast films of PMMA by dielectric spectroscopy: Influence of the nature of the solvent on $\alpha$ and $\beta$ relaxations. International Journal of Adhesion and Adhesives, 1997. 17(3): p. 197-201.

128. Ursache, S., Dielectric Properties and Electromagnetic Behaviour ofPan/Nmpy Conductive Composites. 2013.

129. Medjdoub, A., A. Boubakeur, and T. Lebey. Dielectric Spectrscopy Analysis Behavior of low Density Polyethylene. in 2008 Annual Report Conference on Electrical Insulation and Dielectric Phenomena. 2008.

130. Scarpa, P.C.N., A. Svatík, and D.K. Das-Gupta, Dielectric spectroscopy of polyethylene in the frequency range of $10-5 \mathrm{~Hz}$ to $106 \mathrm{~Hz}$. Polymer Engineering \& Science, 1996. 36(8): p. 1072-1080.

131. Ulrych, J., R. Polanský, and J. Pihera. Dielectric analysis of polyethylene terephthalate (PET) and polyethylene naphthalate (PEN) films. in Proceedings of the 2014 15th International Scientific Conference on Electric Power Engineering (EPE). 2014.

132. Chawla, M., et al., Electrical properties and dielectric spectroscopy of Ar+ implanted polycarbonate. AIP Conference Proceedings, 2015. 1661(1): p. 110005.

133. Ehrlich, P., L.E. Amborski, and R.L. Burton. Dielectric properties of Teflon from room temperature to $314^{\circ} \mathrm{C}$ and from frequencies of $10<$ sup $>2</$ sup $>$ to $10<$ sup $>5</$ sup $>c / s$. in 1953 Conference on Electrical Insulation. 1953.

134. Sencadas, V., et al., Poling of $\beta$-poly(vinylidene fluoride): dielectric and IR spectroscopy studies, in e-Polymers. 2005.

135. Osman, H., et al., Electrical properties of acrylonitrile-butadiene rubber-barium titanate composites AU - Amin, M. Ferroelectrics, 1988. 81(1): p. 387-392.

136. Dul, S., A. Pegoretti, and L. Fambri, Effects of the Nanofillers on Physical Properties of Acrylonitrile-Butadiene-Styrene Nanocomposites: Comparison of Graphene Nanoplatelets and Multiwall Carbon Nanotubes. Nanomaterials, 2018. 8(9): p. 674.

137. Neher, B., et al., Study of the electric properties of palm fiber-reinforced acrylonitrile butadiene styrene composites. Journal of Reinforced Plastics and Composites, 2015. 34(15): p. 1253-1260.

138. Zhang, K., et al., Fabrication and dielectric properties of Ba0.6SrO.4TiO3 / acrylonitrile-butadiene-styrene resin composites. Journal of Materials Science: Materials in Electronics, 2017. 28(12): p. 8960-8968. 
139. Utracki, L.A. and J.A. Jukes, Dielectric studies of poly(vinyl chloride). Journal of Vinyl Technology, 1984. 6(2): p. 85-94.

140. Madbouly, S.A., Broadband Dielectric Spectroscopy for Poly(methyl methacrylate)/Poly( $\alpha$-methyl styrene-co-acrylonitrile) Blend. Polymer Journal, 2002. 34: p. 515.

141. Scarpa, P.C.N., et al. Dielectric spectroscopy measurements on polyethylene aged in AC fields in dry and humid environments. in Proceedings of IEEE Conference on Electrical Insulation and Dielectric Phenomena - (CEIDP'94). 1994.

142. Drakopoulos, S.X., et al., Entanglement dynamics in ultra-high molecular weight polyethylene as revealed by dielectric spectroscopy. Polymer, 2018. 150: p. 3543.

143. Gregorio, R. and E.M. Ueno, Effect of crystalline phase, orientation and temperature on the dielectric properties of poly (vinylidene fluoride) (PVDF). Journal of Materials Science, 1999. 34(18): p. 4489-4500. 